\title{
THE BENEFIT OF SPECTRAL AND POINT-CLOUD DATA FOR HERBAGE YIELD AND QUALITY ASSESSMENT OF GRASSLANDS
}

\author{
M. Wachendorf, T. Astor \\ Grassland Science and Renewable Plant Resources, Universität Kassel, Germany - (mwach, thastor)@ uni-kassel.de
}

ICWG II/III: Pattern Analysis in Remote Sensing

KEY WORDS: Hyperspectral, terrestrial laser scanner, structure from motion, sensor fusion, forage quality, crude protein, acid detergent fibre, grassland management

\begin{abstract}
:
Grassland represents the largest single agricultural vegetation in Germany and provides a multitude of ecosystem services. Timely and accurate information about herbage yield and quality is essential for an efficient use of resources, e.g. to be able to match the actual available feed with a demand of animals or with other industrial uses. Grasslands frequently exhibit small-scale botanical and structural heterogeneity with pronounced spatio-temporal dynamics. These features present particular challenges for sensor applications, which, apart from limitations posed by high costs and low temporal and spatial resolutions of many available remote sensing (RS) systems, may be the reason for so far little commercial applications of RS in practical grassland farming. This paper considers recent developments in the use of spectral and point-cloud data for herbage yield and quality assessment of grasslands. Former research showed that single sensor systems mounted on unmanned aerial vehicles produce similar prediction errors in crude protein or acid detergent fibre concentrations as proximal sensing tools (e.g. field spectroscopy). However, further improvements are needed. Beside improvements of single sensor types, the development of systems with complementary sensors is seen as a promising research area. It will help to overcome the limitations of single sensors and provide better information about herbage yield and quality. From an agronomic point of view, thematic maps of farm fields are suggested as the central outcome of RS and data analysis. These maps are representing the relevant grassland features and therefore can be used as low-cost, appropriate and timely information to support farmers' decision-making.
\end{abstract}

\section{INTRODUCTION}

In Europe, grasslands represent approximately 30 to $35 \%$ of the total agricultural area (Huyghe et al., 2014). Grassland is mainly used for feed provision as forage for ruminants and herbivores and as biomass substrate for energy production. Particularly permanent grasslands are extremely variable in species composition, biodiversity, management practices, as well as in productivity (Lesschen et al., 2014).

A multitude of destructive and non-destructive methods are applied to measure or estimate the production and quality of the forage (Heather, Nature, 1999; t' Mannetje, Jones, 2000; Wachendorf, 2018). Timely and accurate information about forage quality is essential to match actual available feed with animals' demand. For collecting data on herbage yield and quality, traditional techniques based on field measurements (e.g. by cutting and weighing) are the most accurate methods. To achieve representative data for large areas, high number of field measurements is needed. It is labour-intensive and time consuming, particularly on sites that are remote or difficult to access. Further, they are unable to represent variations in the spatial distribution of any biomass parameter. Remote sensing (RS) with its repetitive data collection and digital format, allows fast recording and processing of large quantities of data, making it a most interesting source for estimation of biomass over large areas (Rossini et al., 2012; Kumar et al., 2015).

Information collected by RS systems has different features, such as the spectral, radiometric, spatial, and temporal resolution, and sensors used for biomass and quality estimation vary substantially in these characteristics. Recognizing and understanding the strengths and weaknesses of different types of sensor data are essential for selecting suitable methods for herbage yield and quality estimation. This paper reports recent findings on the potentials of point cloud and spectral data, either obtained by proximal measurements or with sensors based on unmanned aerial vehicles (UAV). Though satellite-borne RS showed interesting developments, uncertain temporal availability of images (e.g. due to unfavourable weather conditions) restricts its applicability in practical grassland management. Thus, satellite-borne RS applications were not covered in the present paper.

Optical RS (i.e. multi- or hyperspectral spectrometry or imaging) is a main source of remotely sensed data for both -herbage yield and quality (Cho, Skidmore, 2009; Cho, Skidmore, Corsi, van Wieren, Sobhan, 2007; Schut et al., 2006; Mutanga, Skidmore, 2004). Point cloud data are frequently used in forests (Collins et al., 2009; Listopad et al., 2015; McGlinchy et al., 2014), but light detection and ranging (LiDAR) sensors and advanced photogrammetric methods (i.e. structure from motion, SfM) may also provide beneficial information on grassland canopy structure. Ultrasonic sensors have a lower spatial resolution than LiDAR, however, they provide promising applications for the assessment of structural characteristics of grassland canopies.

Most studies involving herbage yield and quality estimation from RS data have used a single sensor or single-date image, which may not be sufficient for applications in heterogeneous areas or grasslands with high botanical and structural diversity. Since RS data are available from a range of sensors, each with its own characteristics, a combination of sensors may be beneficial in terms of providing better information on the observed stand. 


\section{ASSESSMENT OF HERBAGE YIELD AND QUALITY IN GRASSLANDS}

\subsection{Herbage yield}

The estimation of herbage yield from point clouds is based on the relationship between sward height (Schulze-Brüninghoff et al. 2019, Wijesingha et al. 2019) or volume (Cooper et al. 2017, Wallace et al. 2017) and biomass. In a recent study, SchulzeBrüninghoff et al. (2019) compared methods based on point cloud derived height and volume parameter and showed that the best correlation was found for fresh (FMY) and dry mater yield (DMY) when height information (i.e. average height in the upper percentiles of the point cloud) were used (adj. $\mathrm{R}^{2}=0.58$ and 0.72 , respectively). Wijesingha et al. (2019) evaluated the potential of terrestrial LiDAR (TLS) based height measurements for estimating FMY and DMY in three different grasslands with different management strategies (i.e. intensive, lenient, extensive) over a full growth period (April to October 2017). Models for predicting DMY achieved better model qualities (nRMSE $=11.6$ to $25.9 \%$ ) than models for FMY (nRMSE $=15.0$ to $29.1 \%$ ). The variation in model quality along the growth period could be explained by the viewing geometry of the emitted laser impulse and thus the occlusion due parts of the vegetation (Wijesingha et al. 2019). In order to create point clouds with a high point density and to reduce the effect of occlusions, several TLS scans from different locations are needed. Schulze-Brüninghoff et al. 2019 showed that two scans from opposite directions already deliver acceptable accuracies. Further scans increase prediction quality of herbage yield only slightly but result in a dramatic increase of the processing time and data volume. Since many scans are needed to cover a larger area (e.g. > 1ha) and the spatial coverage is limited, TLS approaches are not appropriate for large-scale estimation of grassland yield.

To derive point clouds, photogrammetric approaches based on numerous photographs from different viewing angles might be an alternative (Wijesingha et al. 2019, Grüner et al. 2019, Forsmoo et al. 2018, Viljanen et al. 2018, Bareth, Schellberg 2018) to TLS measurements. While point clouds created from TLS have a deeper penetration into the grassland canopy and can also be affected by single plant parts sticking out (e.g. grass flowers/stems), point clouds from SfM approaches are covering rather the upper percentiles of the canopy (Figure 1) and are thus less susceptible for single extreme values.
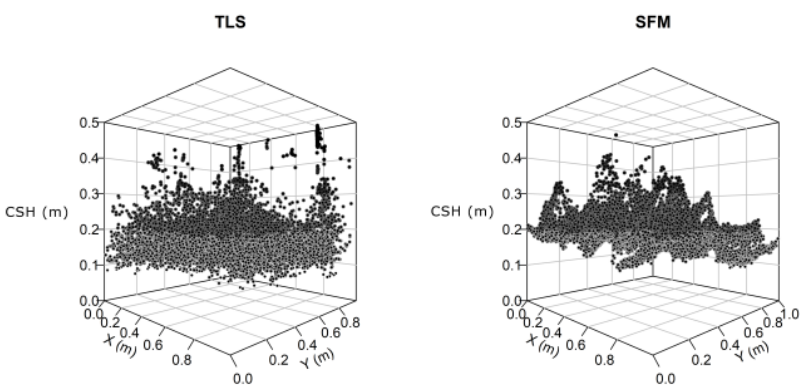

Figure 1: Comparison of point cloud density and penetration depth of TLS (left) and SfM (right) approaches

Traditional field methods for estimating yield in grass swards (e.g. height measurements or the rising plate meter) can also be affected by the canopy structure and are not applicable on large fields. To compensate for this effect, SfM approaches have been proven to deliver equal or even better yield estimations than traditional field methods (Grüner et al. 2019, Bareth, Schellberg 2018). For example, Grüner et al. 2019 showed an improved prediction quality (i.e. lower relative prediction error) for a SfM-based DMY prediction for a clover-grass mixture $(13 \%)$ than predictions based on a large number of height measurements $(r R M S E P=19 \%)$. For a lucerne-grass mixture the predictive performance between the SfM and the manual height measurements was more similar, which could be explained by the different plant architecture of clover and lucerne (Grüner et al. 2019).

Although herbage yield estimations based on satellite spectral data (e.g. Chladil, Nunez 1995) or field spectrometric data (Reddersen et al. 2014) are characterised by a long history, only the recent developments in drone based spectral data collection allows to consider the high spatial variability in yield (Wachendorf et al. 2017). In an experimental approach with two typical legume-grass mixtures (clover-grass and lucerne-grass) a low-cost multispectral camera system (Parrot Sequioa) was mounted on a "off-the-shelf" drone system to predict forage yield along the whole growing period in 2018. The camera operated with four spectral bands (i.e. green, red, rededge, and near-infrared), which all have a spatial resolution of 1.2 megapixel. The camera was equipped with an up-welling sunshine sensor, measuring both incoming radiance along with the irradiance from the ground. This allows a direct conversion from radiance values into reflectance information and makes the camera a robust and easy-to-use tool even under non-perfect light conditions and for multi-temporal measurements. The experiment consisted of 24 plots $(1.5 \mathrm{~m} \times 10 \mathrm{~m})$ containing mixtures of clover-grass and lucerne-grass as well as their pure stands (legumes and grasses). In all plots, biomass samples were taken at nine sampling dates between May and October 2018. Three samplings were made one day before the actual harvest of the complete experiment, which represents the peak in biomass production for these kind of managed grassland types. Prior to each biomass harvest a spectral measurement using the drone system was conducted and the average reflectance of all spectral bands were extracted for each plot. 13 spectral vegetation indices were calculated based on the average reflectance values. Using a machine learning approach, a random forest regression model was calibrated using the average reflectance values and the spectral indices as explanatory variables $(\mathrm{n}=17)$.

The prediction of FMY and DMY showed comparable good results with $\mathrm{R}^{2}$ val $=0.64$ and 0.65 , respectively. The prediction error was below $20 \%$ for both yield measures. The prediction was improved when individual models for clover grass and lucerne grass mixtures were calibrated $\left(\mathrm{nRMSE}_{\mathrm{val}}=0.17\right.$ and 0.14 for clover grass and 0.16 and 0.14 for lucerne grass for FMY and DMY respectively) (Figure 2). The prediction models in combination with the multispectral drone data can subsequently be used to predict FMY and DMY on larger scales (Figure 2).

While multispectral sensors collect reflectance information only for a few single wavelengths, hyperspectral sensors can be used to collect spectral information almost continuously for a certain spectral range (Wachendorf et al. 2017). So far, the potential of hyperspectral drone-based data for predicting herbage yield was rarely examined (de Oliveira et al. 2019, Capolupo et al. 2015). de Oliveira, for example, evaluated the potential of a hyperspectral drone-based system (36 spectral bands) in estimating FMY and DMY in a highly intensive grassland experiment. The authors found very low prediction errors of approx. $5 \%$ for FMY and $2.5 \%$. for DMY. A reason for this exceptional low prediction error is the very small variation in the yield (de Oliveira et al. 2019). In another study eight grasslands with different management practices were sampled with a hyperspectral full-frame camera (124 bands, 450-950 nm) 
close to their harvest (Astor et al. in prep.). The study sites were located in central Germany and included seven extensive grasslands in nature protected areas with one cut (at three different cutting dates between 15 Jun and 15 July) and no fertilisation, and one intensively used fertilized grassland. The intensively used grassland was cut up to three times. Thus, together ten datasets along the growth period in 2018 were obtained and included in a Cubist regression model (Quinland, 1992). Using 100 times repeating cross-validation with keeping $25 \%$ of the samples out for validation at each run, the prediction model for FMY and DMY was evaluated.

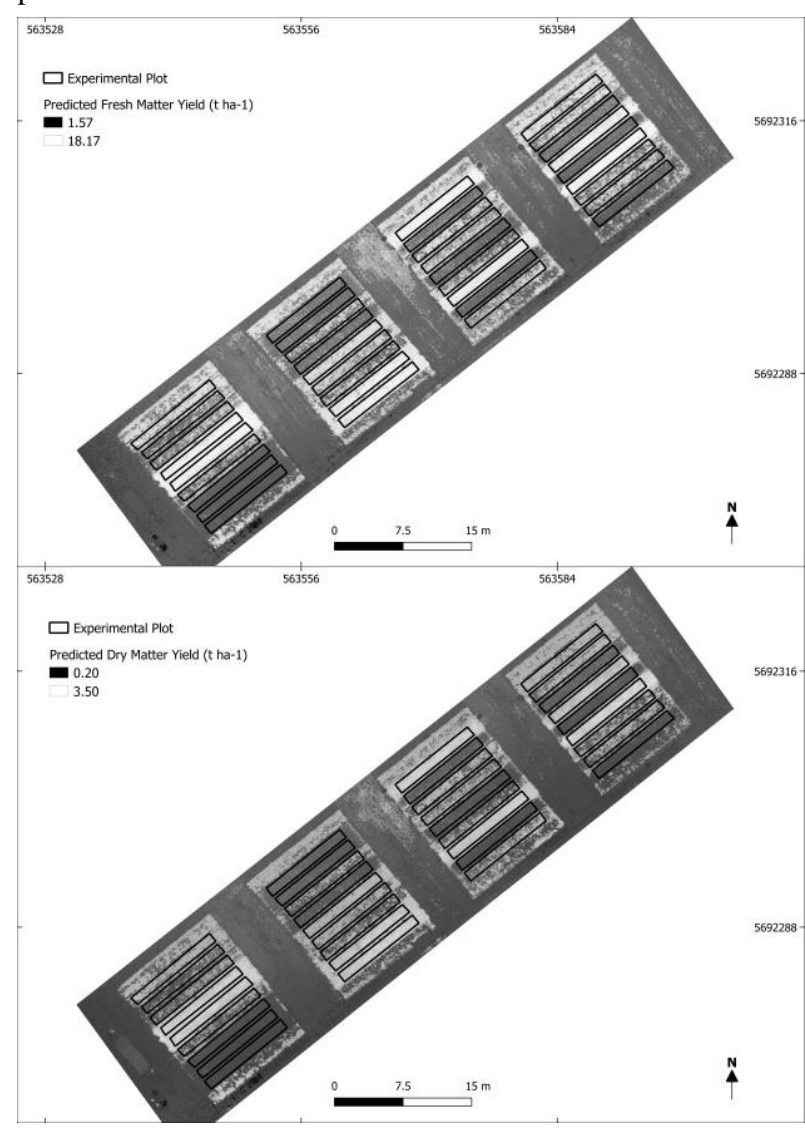

Figure 2: Predicted fresh matter (top) and dry matter yield (bottom) maps for the experimental layout (Grüner et al. 2019) for the second sampling date (June 2018). Predicted values are

based on a random forest regression model using spectral reflectance of the green, red, rededge, and NIR bands as well as 14 spectral indices

The median $\mathrm{R}^{2}$ val for fresh matter biomass was 0.86 and for DMY the $\mathrm{R}^{2}$ val was 0.76 . The relative prediction error was $39 \%$ and $36 \%$, respectively. The error indicates that still some portion of the total variation in the grassland yield cannot be predicted using spectral information solely. A reason could be the vegetation density close to the harvest dates which leads to saturation effects of the incoming radiation and thus to a disturbance of the biomass-reflectance relationship. Furthermore, nature conservation grasslands close to their harvest dates are already quite mature (i.e. high proportion of dead material). It also can hamper the prediction of yield using spectral reflectance information (Wachendorf et al. 2017).

As an approach to compensate for these kind of saturation effects the fusion of datasets from different sensors can be tested. Data from sensors detecting different vegetation characteristics like structural characteristics derived from point cloud and biochemical characteristics derived from spectral information should be used (Wachendorf et al. 2017). When combining information from two or more sensor systems, classic ordinary linear regression approaches will not work due to, among other things, the high number of inter-correlated explanatory variables. In this case machine learning approaches have been shown to have a great potential (Möckel et al. 2017, Safari et al. 2016). In a recent study four machine learning methods (support vector machines, random forest, partial least squares and gradient boosting machines) were tested for their prediction quality of FMY and DMY. TLS and drone based hyperspectral measurements were used solely and in combination. All machine learning methods revealed lower prediction errors and higher $\mathrm{R}^{2}$ val values when the information of both sensor techniques was used together (Figure 3), confirming the expectation of better prediction performance when sensor data fusion is used (Wachendorf et al. 2017).

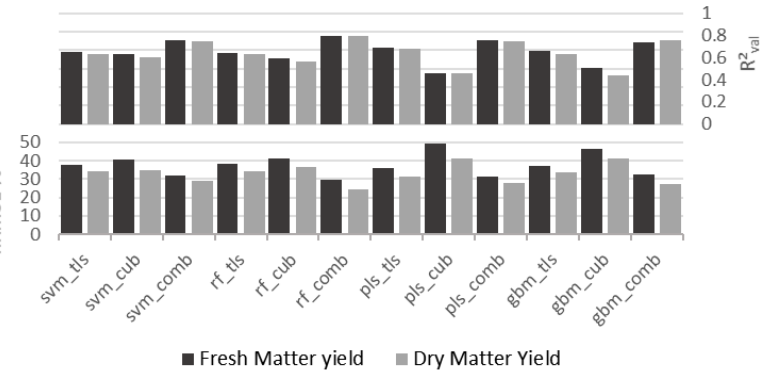

Figure 3: Prediction model quality for fresh matter yield (black) and dry matter yield (grey) for four machine learning methods (svm: support vector machines, rf: random forest, pls: partial least squares, gbm: gradient boosting machines) using only point cloud data (tls), hyperspectral data (cub), or both datasets together (comb)

The best prediction performance for both FMY and DMY was achieved by using the random forest regression ( $\mathrm{rRMSE}=29.5$, 24.7 and $\mathrm{R}^{2}=0.80,0.80$ for FMY and DMY respectively). Overall, the prediction quality of herbage yield using remote sensing data is very good. However, the prediction accuracies in the future need to be improved to make drone based remote sensing approaches applicable in practical agricultural grassland management. For this a combination of remote sensing data with grassland yield models (Taubert et al. 2012) might lead to the necessary model qualities.

\subsection{Herbage quality}

For herbage quality monitoring and mapping techniques ranging from satellite RS to field spectroscopy and from optical RS to synthetic aperture radar have been used (Ali et al., 2016; Wachendorf, 2017). However, the most of studies with RS based forage quality estimation have utilised field spectroscopy, which collects point level spectral reflectance data between visible to short-wave infrared areas of the electromagnetic spectrum. Crude protein $(\mathrm{CP})$, nitrogen $(\mathrm{N})$, neutral detergent fibre (NDF) and acid detergent fibre (ADF), indicating the less digestible part of fibre constituents, are the most common forage quality parameters that have been estimated using field spectroscopy data for different grasslands with significant accuracy (Biewer et al., 2009; Mutanga et al., 2004; Pullanagari et al., 2012; Ramoelo et al., 2013b).

Spectral images were acquired from eight grasslands in the mountainous region of northern Hesse, Germany (ranging between 135 and 846 m.a.s.l.), which strongly differed in 
management practices and composition of species. A hyperspectral snapshot camera (Cubert Hyperspectral Firefly S185 SE (Cubert GmbH, Ulm, Germany) with 126 bands between 450 - $950 \mathrm{~nm}$ was used, which was attached to an UAV. From various predictive modelling regression algorithms tested, support vector regression (SVR) provided the highest precision and accuracy for CP estimation (median nRMSEp = $9.6 \%$; median $\left.\mathrm{R}^{2}=0.81\right)$, while the cubist regression $(\mathrm{CBR})$ model provided the best estimation of ADF (median nRMSEp = $13.0 \%$; median $\mathrm{R}^{2}=0.60$ ). The plots of fit for the bestperforming models show the model fits across all grasslands (Figure 4). Overall, prediction accuracy tended to be lower at higher levels of $\mathrm{CP}$, whereas for ADF the accuracy was consistent across the whole range of observed values. Similar relative error pattern for $\mathrm{CP}$ and $\mathrm{ADF}$ estimation models was obtained in previous studies that utilised field spectroscopy data (Kawamura et al., 2008; Pullanagari et al., 2012; Safari et al., 2016). Further analysis showed that the wavelength $(718 \mathrm{~nm})$ which obtained the highest linear correlation with $\mathrm{CP}$ turned out to be the most crucial wavelength for both - best-performing $\mathrm{CP}$ and $\mathrm{ADF}$ models. However, the identified first most important wavelengths were not related to any foliar chemical absorption feature, such as chlorophyll, protein or cellulose (Curran, 1989). According to Curran (1989), the absorption features that relate to $\mathrm{CP}$ and $\mathrm{ADF}$ can be found at wavelengths in the shortwave infrared region of the spectrum $(1400-3000$ $\mathrm{nm}$ ). Singh et al. (2017) also confirmed that important wavelengths for ADF were in the shortwave infrared region of the spectrum. The camera used in the present study did not capture shortwave infrared bands.

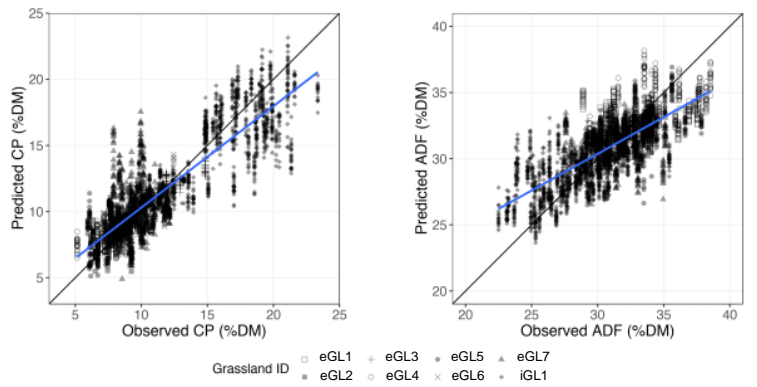

Figure 4: Observation vs prediction scatter plots from the resulting models for $\mathrm{CP}$ (left) and $\mathrm{ADF}$ (b) concentrations in different grasslands. Symbols represent different grasslands. The dashed line is the 1:1 line and the solid line represents the linear regression between observed and predicted values. Shown are 100 different model runs used in the model training and testing phase

To calibrate ultrasonic and hyperspectral reflectance sensors, Safari et al. (2016) used extremely heterogeneous pastures continuously grazed by cows with three stocking density treatments (moderate, lenient and very lenient stocking). Hyperspectral analysis by a modified partial least square regression (MPLS) resulted in maximum accuracy for the prediction of $\mathrm{ADF}$ and $\mathrm{CP}\left(\mathrm{R}^{2} \mathrm{CV}=0.63-0.85\right)$. Any reduction of hyperspectral data into vegetation indices based on few specific narrow wavebands or satellite broadbands reduced prediction accuracy significantly. However, prediction of ADF and CP was improved by a combined analysis of ultrasonic sward height and vegetation indices (Table 1), so that most calibration models exceeded an RPD value (Ratio of standard deviation and standard error of prediction) of 1.4, which is considered as an acceptable predicting capability for variable field conditions.
Table 1. Cross-validation results for prediction of ADF and $\mathrm{CP}$ in the biomass of heterogeneous pastures from ultrasonic sward height (USH) the normalised difference spectral index (NDSI)

exclusively and as a combination of both (USH + NDSI).

Values in bold indicate best model approaches (adjusted from Safari et al., 2016).

\begin{tabular}{|c|c|c|c|c|}
\hline & & $\begin{array}{c}\text { USH } \\
\mathrm{R}^{2} \mathrm{CV} / \mathrm{SE}_{\mathrm{CV}}\end{array}$ & $\begin{array}{c}\text { NDSI } \\
\mathrm{R}^{2} \mathrm{CV} / \mathrm{SE}_{\mathrm{CV}}\end{array}$ & $\begin{array}{c}\text { USH+NDSI } \\
\mathrm{R}^{2}{ }_{\mathrm{CV}} / \mathrm{SE}_{\mathrm{CV}}\end{array}$ \\
\hline ADF & Spring & $0.50 / 2.95$ & $0.45 / 3.12$ & $\mathbf{0 . 6 8} / \mathbf{2 . 1 9}$ \\
\hline & Summer & $0.29 / 5.33$ & $0.63 / 3.90$ & $\mathbf{0 . 6 6} / \mathbf{3 . 7 9}$ \\
\hline & Autumn & $0.28 / 5.34$ & $0.46 / 4.55$ & $\mathbf{0 . 6 1} / \mathbf{3 . 8 2}$ \\
\hline CP & Spring & $0.03 / 1.89$ & $0.41 / .1 .41$ & $\mathbf{0 . 4 5} / \mathbf{1 . 3 9}$ \\
\hline & Summer & $0.03 / 3.59$ & $\mathbf{0 . 8 4} / .1 .42$ & n.s. \\
\hline & Autumn & n.s. & $\mathbf{0 . 6 0} / \mathbf{1 . 9 5}$ & n.s. \\
\hline
\end{tabular}

\section{CONCLUSIONS}

This paper considers recent developments in using spectral and point-cloud data for herbage yield and quality assessment of grasslands. Even if single sensor systems mounted on unmanned aerial vehicles compared to proximal sensing tools (e.g. field spectroscopy) produce similar prediction errors in crude protein or acid detergent fibre concentrations, there is still a need for further improvements. Beside improvements of single sensor types, the development of systems with complementary sensors must be advanced to help overcoming the limitations of single sensors and to provide better information about herbage yield and quality.

Though few studies prove the multi-site validity of RS models for the estimation of herbage yield and quality, many grassland types are still not considered (i.e. wet or intensively managed grasslands) and heterogeneous pastures still represent a major challenge. Disruptive grassland features (e.g. senesced plant material, soil signals, animal excrements) are difficult to assess or to filter out. Spectral unmixing or deep learning methods may offer interesting perspectives.

From an agronomic point of view, the central outcome of RS and data analysis are thematic maps of farm fields showing the relevant grassland features. Produced maps can be used to support various farm management decisions. These include measures at the (i) strategic level, where long-term decisions are made based on aggregated data over time regarding future scenarios created from downscaled climate scenarios (e.g., farm infrastructure planning); (ii) tactical level, where medium-term decisions are made (e.g., evaluation of clover dry-matter contribution in pastures and choice of crop species for oversowing); and (iii) operational level, where farmers make day-to-day decisions based on spatially explicit real-time data on yield and quality of pastures (e.g., planning of ration, pasture rotation and fertilizer application). Eventually, the overarching goal will be to provide cheap, appropriate and timely information to farmers to support decision-making.

\section{ACKNOWLEDGMENTS}

The authors are grateful to E. Grüner, J. Wijesingha, D. Schulze-Brüninghoff and M. Wengert for providing sensor data and analysis. We thank A. Gerke for coordination and implementation of field work.

\section{REFERENCES}

Ali, I., Cawkwell, F., Dwyer, E., Barrett, B., Green, S., 2016. Satellite remote sensing of grasslands: from observation to 
management - a review. J. Plant Ecol. 9, 649-671. doi:10.1093/jpe/rtw005.

Bareth, G., Schellberg, J., 2018: Replacing Manual Rising Plate Meter Measurements with Low-cost UAV-Derived Sward Height Data in Grasslands for Spatial Monitoring. PFG $J$. Photogramm. Remote Sens. Geoinf. Sci. 2018, 86, 157-168. doi.org/10.1007/s41064-018-0055-2

Biewer, S., Fricke, T., Wachendorf, M., 2009. Development of canopy reflectance models to predict forage quality of legumegrass mixtures. Crop Sci. 49, 1917-1926. doi:10.2135/cropsci2008.11.0653.

Capolupo, A., Kooistra, L., Berendonk, C., Boccia, L., Suomalainen, J., 2015: Estimating Plant Traits of Grasslands from UAV-Acquired Hyperspectral Images: A Comparison of Statistical Approaches. ISPRS Int. J. Geo-Inf. 4, 2792-2820. doi.org/10.3390/ijgi4042792

Cho, M. A., and Skidmore, A. K., 2009: Hyperspectral predictors for monitoring biomass production in Mediterranean mountain grasslands: Majella National Park, Italy. International Journal of Remote Sensing 30(2), 499-515. doi.org/10.1080/01431160802392596

Chladil, M. A. and Nunez, M., 1995: 'Assessing grassland moisture and biomass in Tasmania. The application of remote sensing and empirical models for a cloudy environment,', Int. J. Wildland Fire. 5, 165-171. doi.org/10.1007/s10661-005-1611-y

Cho, M. A., Skidmore, A., Corsi, F., van Wieren, S. E., \& Sobhan, I., 2007: Estimation of green grass/herb biomass from airborne hyperspectral imagery using spectral indices and partial least squares regression. International Journal of Applied Earth Observation and Geoinformation 9(4), 414-424. doi.org/10.1016/j.jag.2007.02.001.

Curran, P.J., 1989: Remote sensing of foliar chemistry. Remote Sens. Environ. 30, 271-278. doi:10.1016/0034-4257(89)900692.

Collins, J. N., Hutley, L. B., Williams, R. J., Boggs, G., Bell, D. \& Bartolo, R., 2009: Estimating landscape-scale vegetation carbon stocks using airborne multi-frequency polarimetric synthetic aperture radar, SAR) in the savannahs of north Australia. International Journal of Remote Sensing 30(5), 1141-1159. doi.org/10.1080/01431160802448935.

Cooper, S.D., Roy, D.P., Schaaf, C.B., Paynter, I., 2017: Examination of the potential of terrestrial laser scanning and structure-from-motion photogrammetry for rapid nondestructive field measurement of grass biomass. Remote Sens. 9. doi.org/ $10.3390 /$ rs9060531.

de Oliveira, R. A., Näsi, R., Niemeläinen, O., Nyholm, L., Alhonoja, K., Kaivosoja, J., Viljanen, N., Hakala, T., Nezami, S., Markelin, L. Jauhuaunen, L. Honkavaara, E., 2018: Assessment of rgb and hyperspectral uav remote sensing for grass quantity and quality estimation. International Archives of the Photogrammetry, Remote Sensing and Spatial Information Sciences, Volume XLII-2/W13., 1305-1310. doi.org/10.5194/isprs-archives-XLII-3-1305-2018

Forsmoo, J., Anderson, K., Macleod, C.J.A., Wilkinson, M.E., Brazier, R., Smit, I., 2018: Drone-based structure-from-motion photogrammetry captures grassland sward height variability. $J$. Appl. Ecol. 94, 237. DOI: 10.1111/1365-2664.13148

Grüner E., Astor T., Wachendorf M., 2019: Biomass Prediction of Heterogeneous Temperate Grasslands Using an SfM Approach Based on UAV Imaging. Agronomy 2019, 9(2), 54. doi.org/10.3390/agronomy9020054

Heather, R., Nature, E., 1999: Grassland Monitoring, in: Crofts, A., Jefferson, R.G., (Eds.), Lowland Grassland Management Handbook. English Nature, pp. 15:1-15:21.

Huyghe C., De Vliegher A., Van Gils B. and Peeters A., 2014: Grasslands and herbivore production in Europe and effects of common policies. Les Editions Quae, Centre INRA de Versailles France, pp. 300

Kawamura, K., Watanabe, N., Sakanoue, S., Inoue, Y., 2008: Estimating forage biomass and quality in a mixed sown pasture based on partial least squares regression with waveband selection. Grassl. Sci. 54, 131-145. doi:10.1111/j.1744697X.2008.00116.x.

Kumar, L., Sinha, P., Taylor, S., \& Alqurashi, A. F., 2015: Review of the use of remote sensing for biomass estimation to support renewable energy generation. Journal of Applied Remote Sensing, 9(1), 97696. doi: 10.1117/1.JRS.9.097696.

Lesschen, J.P., Elbersen, B.S., Hazeu, G.W., van Doorn, A., Mucher, C.A., Velthof, G.L., 2014: Defining and classifying grasslands in Europe - Task 1. Wageningen.

Listopad, C. M. C. S., Masters, R. E., Drake, J., Weishampel, J., \& Branquinho, C., 2015: Structural diversity indices based on airborne LiDAR as ecological indicators for managing highly dynamic landscapes. Ecological Indicators 57, 268-279. doi.org/10.1016/j.ecolind.20.

McGlinchy, J., van Aardt, J. A. N., Erasmus, B., Asner, G. P., Mathieu, R., Wessels, K., \& Cawse-Nicholson, K., 2014: Extracting structural vegetation components from smallfootprint waveform lidar for biomass estimation in savanna ecosystems. IEEE Journal of Selected Topics in Applied Earth Observations and Remote Sensing, 7(2), 480-490. doi.org/10.1109/JSTARS.2013.2274761.

Moeckel T., Safari H., Reddersen B., Fricke T., Wachendorf M., 2017: Fusion of Ultrasonic and Spectral Sensor Data for Improving the Estimation of Biomass in Grasslands with Heterogeneous Sward Structure. Remote Sens. 2017 9(1), 98. doi.org/10.3390/rs9010098

Mutanga, O., Skidmore, A.K., Prins, H.H.T., 2004: Predicting in situ pasture quality in the Kruger National Park, South Africa, using continuum-removed absorption features. Remote Sens. Environ. 89, 393-408. doi:10.1016/j.rse.2003.11.001

Mutanga, O., \& Skidmore, A. K., 2004: Integrating imaging spectroscopy and neural networks to map grass quality in the Kruger National Park, South Africa. Remote Sensing of Environment 90(1), 104-115. doi.org/10.1016/j.rse.2003.12.004.

Pullanagari, R.R., Yule, I.J., Tuohy, M.P., Hedley, M.J., Dynes, R.A., King, W.M., 2012: In-field hyperspectral proximal sensing for estimating quality parameters of mixed pasture. Precis. Agric. 13, 351-369. doi:10.1007/s11119-011-9251-4. 
Quinlan, J.R., 1992: Learning with continuous classes. In Proceedings of the $5^{\text {th }}$ Australian Joint Conference on Artificial Intelligence, Hobart, Tasmania, 16-18 November 1992, pp. 343-348.

Ramoelo, A., Skidmore, A.K., Cho, M.A., Mathieu, R., Heitkönig, I.M.A., Dudeni-Tlhone, N., Schlerf, M., Prins, H.H.T., 2013: Non-linear partial least square regression increases the estimation accuracy of grass nitrogen and phosphorus using in situ hyperspectral and environmental data. ISPRS J. Photogramm. Remote Sens. 82, 27-40. doi:10.1016/j.isprsjprs.2013.04.012

Reddersen B., Fricke T., Wachendorf M., 2014: A multi-sensor approach for predicting biomass of extensively managed grassland. Computers and Electronics in Agriculture 109, 247260. doi.org/10.1016/j.compag.2014.10.011

Rossini, M., Cogliati, S., Meroni, M., Migliavacca, M., Galvagno, M., Busetto, L., Colombo, R., 2012: Remote sensingbased estimation of gross primary production in a subalpine grassland. Biogeosciences 9(7), 2565-2584. doi: 10.5194/bg-92565-2012.

Safari H., Fricke T., Reddersen B., Möckel T., Wachendorf M., 2016: Comparing mobile and static assessment of biomass in heterogeneous grassland with a multi-sensor system. J. Sens. Sens. Syst. 5, 301-312. doi.org/10.1016/j.jag.2018.10.006

Safari, H., Fricke, T., Wachendorf, M., 2016: Determination of fibre and protein content in heterogeneous pastures using field spectroscopy and ultrasonic sward height measurements. Comput. Electron. Agric. 123, 256-263. doi:10.1016/j.compag.2016.03.002.

Schulze-Brüninghoff D., Hensgen F., Wachendorf M., Astor T., 2019: Methods for LiDAR-based estimation of extensive grassland biomass. Computer and Electronics in Agriculture 156, 693-699. doi.org/10.1016/j.compag.2018.11.041

Schut, A. G. T., van der Heijden, G. W. A. M., Hoving, I., Stienezen, M. W. J., van Evert, F. K., \& Meuleman, J., 2006: Imaging spectroscopy for on-farm measurement of grassland yield and quality. Agronomy Journal 98(5), 1318-1325. doi.org/10.2134/agronj2005.0225.

Singh, L., Mutanga, O., Mafongoya, P., Peerbhay, K., 2017: Remote sensing of key grassland nutrients using hyperspectral techniques in KwaZulu-Natal, South Africa. J. Appl. Remote Sens. 11, 036005. doi:10.1117/1.JRS.11.036005.

t' Mannetje, L., Jones, R., 2000: Field and Laboratory Methods for Grassland and Animal Production Research. CABI Publishing, Oxon, UK.

Taubert, F., Frank, K., Huth, A., 2012: A review of grassland models in the biofuel context. Ecol. Model. 245, pp. 84-93. doi.org/10.1016/j.ecolmodel.2012.04.007

Viljanen, N., Honkavaara, E., Näsi, R., Hakala, T., Niemeläinen, O., Kaivosoja, J., 2018: A Novel Machine Learning Method for Estimating Biomass of Grass Swards Using a Photogrammetric Canopy Height Model, Images and Vegetation Indices Captured by a Drone. Agriculture 8, 70. doi.org/10.3390/agriculture 8050070
Wachendorf, M., 2018: Advances in remote sensing for monitoring grassland and forage production, in: Marshal, A., Collins, R. (Eds.), Improving Grassland and Pasture Management in Temperate Agriculture. Burleigh Dodds Science Publishing, Cambridge.

Wachendorf, M., Fricke, T., Möckel, T., 2017: Remote sensing as a tool to assess botanical composition, structure, quantity and quality of temperate grasslands. Grass Forage Sci. 1-14. doi:10.1111/gfs.12312.

Wallace, L., Hillman, S., Reinke, K., Hally, B., 2017: Nondestructive estimation of aboveground surface and near-surface biomass using 3D terrestrial remote sensing techniques. Methods Ecol. Evol. doi.org/10.1111/2041-210X.12759

Wijesingha J, Moeckel T., Hensgen F., Wachendorf M., 2019: Evaluation of 3D point cloud-based models for the prediction of grassland biomass. International Journal of Applied Earth Observation and Geoinformation 78, 352-359. doi.org/10.1016/j.jag.2018.10.006 